\title{
Oil Chromatographic Analysis and Fault Diagnosis Case Analysis for Transformers
}

\author{
Yanping $\mathrm{Li}^{1 *}$, Yong $\mathrm{Li}^{2}$, Yunqi $\mathrm{Li}^{3}$ \\ ${ }^{1}$ State Grid of China Technology College, No.500 South Erhuan Road, Jinan City, Shandong Province, 250002,China \\ ${ }^{2}$ State Grid Shandong Electric Power Company,No.1jop50 Jinger Rd, shizhong district,Jinan,Shandong,250001, China \\ ${ }^{3}$ Chongqing University, No.174 Shazheng Street, shapingba district, chongqing,400044,China
}

\begin{abstract}
The production principle of characteristic gas in transformer oil and its corresponding transformer fault type are discussed in this paper. Aiming at the fault of multiple characteristic gases exceeding the standard in a $110 \mathrm{kV}$ transformer oil, this paper analyzed the fault reasons according to the characteristic gas method and the three-ratio method, and combined with relevant tests, it was judged that the transformer core multiple grounding fault caused the fault. The on-site inspection verifies the correctness of the failure analysis results and the corresponding measures were adopted to eliminate the transformer faults.
\end{abstract}

\section{Introduction}

Transformer oil is widely used in electric equipments such as transformers, reactors and transformers. Transformer oil is the main insulation of oil-immersed transformer. In addition to its functions of insulation and cooling, it is also the carrier of information about internal defects of transformers. The latent fault of transformer can be found by chromatographic analysis of dissolved gas in transformer oil. Partial overheat and partial discharge will cause the breakdown of transformer oil and solid insulation, which will produce gas. The amount of gas produced increases with the increase of the energy density at the fault point. When the content of the characteristic gas in the transformer oil exceeds the specified attention value, Follow-up analysis should be performed. The character and type of fault can be determined by the method of characteristic gas judgment. Guide for analysis and determination of dissolved gases in transformer oil. ${ }^{[1]}$ When the concentration of some characteristic component gases in the running transformer oil reaches a certain value, for example, $\varphi\left(\mathrm{C}_{1}+\mathrm{C}_{2}\right)>150 \mu \mathrm{L} / \mathrm{L} \quad$ or $\quad \varphi\left(\mathrm{C}_{2} \quad \mathrm{H}_{2}\right)>5 \mu \mathrm{L} / \mathrm{L} \quad$ or $\varphi(\mathrm{H} 2)>150 \mu \mathrm{L} / \mathrm{L}$, attention should be paid to the transformer. But it does not mean that there must be a transformer fault at this time. We need to combine the historical data to synthetically judge the running state of the transformer. ${ }^{[2]}$

\section{The relation between gas production and fault of transformer}

Electrical or thermal failure can cause some C-H and C-C bonds in transformer oil to break, with the formation of small amounts of reactive hydrogen atoms and unstable hydrocarbon radicals. Through complex chemical reactions, $\mathrm{H}_{2}$ and low molecular hydrocarbon gases are formed. A small amount of $\mathrm{CO}$ and $\mathrm{CO}_{2}$ is produced when the transformer oil is oxidized.

\subsection{Gases produced by different fault types}

The characteristic gas components of different transformer faults are different, and the fault type can be judged by table 1 . At the same time, it should be noted that moisture in the water or gas bubbles in the oil may increase the hydrogen content. ${ }^{[2]}$

Table 1 Gases produced by different fault types

\begin{tabular}{c|l|l}
\hline Fault type & \multicolumn{1}{|c}{ Main gas composition } & \multicolumn{1}{c}{ Secondary Gas composition } \\
\hline oil superheat & $\mathrm{CH}_{4}, \mathrm{C}_{2} \mathrm{H}_{4}$ & $\mathrm{H}_{2}, \mathrm{C}_{2} \mathrm{H}_{6}$ \\
\hline oil and paper superheat & $\mathrm{CH}_{4}, \mathrm{C}_{2} \mathrm{H}_{4}, \mathrm{CO}, \mathrm{CO}_{2}$ & $\mathrm{H}_{2}, \mathrm{C}_{2} \mathrm{H}_{6}$ \\
\hline Oil and insulation paper partial discharge & $\mathrm{H}_{2}, \mathrm{CH}_{4}, \mathrm{CO}$ & $\mathrm{C}_{2} \mathrm{H}_{2}, \mathrm{C}_{2} \mathrm{H}_{6}, \mathrm{CO}_{2}$ \\
\hline Spark discharge in oil & $\mathrm{H}_{2}, \mathrm{C}_{2} \mathrm{H}_{2}$ & \\
\hline Arc in oil & $\mathrm{H}_{2}, \mathrm{C}_{2} \mathrm{H}_{2}$ & $\mathrm{CH}_{4}, \mathrm{C}_{2} \mathrm{H}_{4}, \mathrm{C}_{2} \mathrm{H}_{6}$ \\
\hline Electric arc in oil and insulating paper & $\mathrm{H}_{2}, \mathrm{C}_{2} \mathrm{H}_{2}, \mathrm{CO}, \mathrm{CO}_{2}$ & $\mathrm{CH}_{4}, \mathrm{C}_{2} \mathrm{H}_{4}, \mathrm{C}_{2} \mathrm{H}_{6}$ \\
\hline
\end{tabular}




\subsection{The relation between transformer fault gas and transformer fault temperature}

Transformers and other oil-filled equipment in normal operating conditions, The heat produced is not enough to break carbon bonds or dehydrogenate hydrocarbons. When there are some faults in the equipment, the energy generated can break the bonds of hydrocarbon compounds and produce low molecular hydrocarbons or hydrogen. The pyrolysis gas at low temperature is dominated by saturated hydrocarbon, while the pyrolysis gas at high temperature is dominated by alkenes. The relationship between the type of gas produced by the fault and the fault temperature is shown in figure 1. With the increase of fault energy, the sequence of components in pyrolysis gas is alkanes, alkenes and alkynes. ${ }^{[3]}$

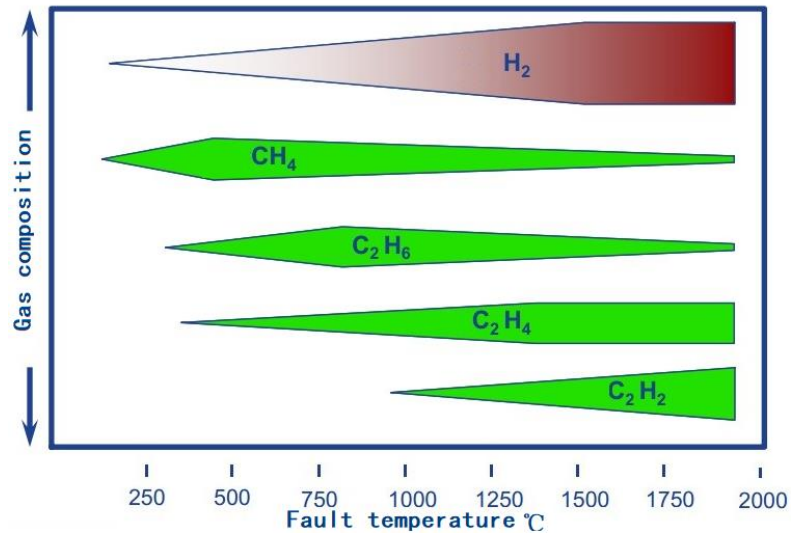

Figure 1 The relationship between the gas composition and the fault temperature

\subsection{Three-ratio method}

According to the different ratios of the volume fractions of characteristic gases, the codes are according to the rules in table 3. According to DL/T722-2014 Guide to the analysis and the diagnosis of gases dissolved in transformer oil, we can determine the transformer fault type and general position.

Table 2 Coding rules of three ratio method

\begin{tabular}{c|c|c|c|c}
\hline Ratio & $<0.1$ & $0.1 \sim 1$ & $1 \sim 3$ & $\geq 3$ \\
\hline $\begin{array}{c}\varphi(\mathrm{C} 2 \mathrm{H} 2) / \varphi(\mathrm{C} \\
2 \mathrm{H} 4)\end{array}$ & 0 & 1 & 1 & 2 \\
\hline$\varphi(\mathrm{CH} 4) / \varphi(\mathrm{H} 2)$ & 1 & 0 & 2 & 2 \\
\hline $\begin{array}{c}\varphi(\mathrm{C} 2 \mathrm{H} 4) / \varphi(\mathrm{C} 2 \\
\mathrm{H} 6)\end{array}$ & 0 & 0 & 1 & 2 \\
\hline
\end{tabular}

\section{Transformer fault judgment case}

\subsection{Device information}

Transformer No.1 of $110 \mathrm{kV}$ substation, equipment model: sz11-50000 / 110, manufacturer: Yantai Dongyuan Transformer Co., Ltd., ex factory date: June 2014, put into operation date: November 2014.

\subsection{Failure}

In September 2018, oil chromatogram analysis of No.1 transformer showed that hydrogen, carbon monoxide, carbon dioxide and hydrocarbon gas all increased significantly, acetylene content was $7.16 \mathrm{ul} / 1$, specific detection results are shown in Table 5 , which can be used to judge internal fault of transformer.

Table 3 Chromatogram Analysis results of No.1 transformer oil(uL/L)

\begin{tabular}{c|c|c|c|c|c|c|c|c}
\hline Gas & $\mathrm{H}_{2}$ & $\mathrm{CO}$ & $\mathrm{CO}_{2}$ & $\mathrm{CH}_{4}$ & $\mathrm{C}_{2} \mathrm{H}_{4}$ & $\mathrm{C}_{2} \mathrm{H}_{6}$ & $\mathrm{C}_{2} \mathrm{H}_{2}$ & $\mathrm{C}_{1}+\mathrm{C}_{2}$ \\
\hline History Data & 62 & 120.1 & 237.2 & 7.79 & 1.26 & 1.6 & 0 & 10.65 \\
\hline Fault status data & 130 & 352.4 & 765.3 & 50.4 & 176.2 & 62.3 & 7.16 & 296.06 \\
\hline
\end{tabular}

\subsection{Treatment measures}

On September 17, the company arranged a power outage maintenance for the transformer, and the tester conducted a diagnostic test on the transformer. Test items include DC resistance, bushing dielectric loss, winding dielectric loss, short circuit impedance and insulation items. Among them, the data of transformer DC resistance, bushing dielectric loss and insulation resistance, winding ring loss and insulation resistance meet the requirements of the regulations, and the data are normal.

When measuring the insulation resistance of iron core, the tester shall disconnect the grounding wire of iron core and test the insulation resistance of iron core with a $2500 \mathrm{~V}$ megohmmeter, It is found that the insulation resistance of iron core is only $0.02 \mathrm{M} \Omega$, which is far less than the specification requirements of $100 \mathrm{~m} \Omega$, and the voltage of the insulation resistance meter can only be increased to $72 \mathrm{~V} .{ }^{[4]}$ The tester determined that the iron core had multiple grounding faults. The tester used a capacitor with a capacity of 2.27 uf to conduct current impact on the core grounding point of No.1 transformer. First, the tester uses $5000 \mathrm{v}$ electronic insulation resistance meter to charge the capacitor for 1 minute Before the impact. Next, the core of the transformer is discharged with a large current and impact iron core multi-point grounding point. Finally, the insulation resistance of iron core is measured again. Insulation resistance of transformer core is $0.1 \mathrm{M} \Omega$. The results show that there is still a problem of multi-point grounding in the iron core. ${ }^{[5]}$

Therefore, the transformer Therefore, the transformer maintenance personnel decided to disassemble and inspect the No.1 transformer decided to disassemble and inspect the No.1 transformer. They found that a large amount of steel emery used for sandblasting was left inside the transformer, as shown in Figure 2. This is because the transformer was not completely cleaned after sand blasting by the production company. A small 
amount of steel emery is left inside the transformer. As a result, No. 1 transformer had core multi-point grounding fault. After the transformer maintenance personnel remove the steel emery by magnet adsorption, as shown in Figure 3. After all the steel emery is removed, the transformer operates normally.

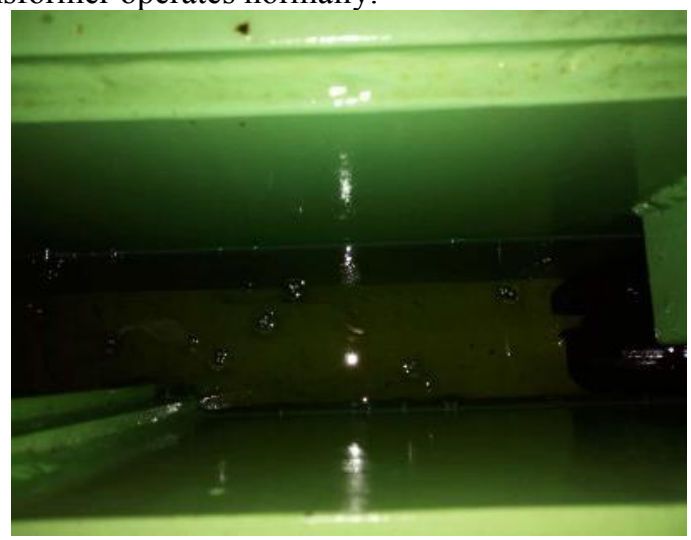

Figure 2 Steel emery left inside the transformer

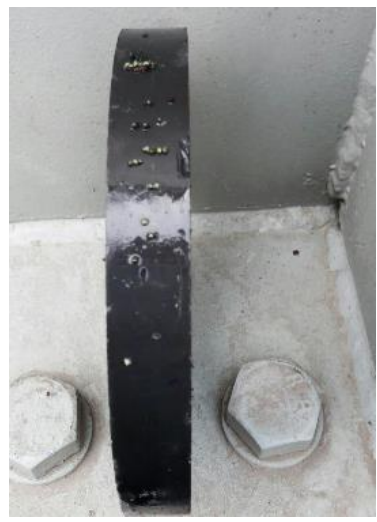

Figure 3 Steel emery adsorbed on magnet

\section{Summary}

The types and concentrations of various characteristic gases in transformer oil are closely related to the internal faults of the transformer. Three-ratio method is an effective judgment method. Through the gas chromatography analysis of transformer oil and the three-ratio data, internal faults of transformer can be found effectively and early. Special attention should be paid to the fact that the analysis of transformer chromatographic test results should be compared with historical test data to judge whether there is a fault. At the same time, it is necessary to make a comprehensive judgment based on the test results of other electrical test items, so as to make a correct judgment on the nature and location of the fault. In the transformer fault analysis cases discussed in this paper, $\mathrm{We}$ use the gas chromatography analysis results of transformer oil and combine the test results of DC resistance, bushing dielectric loss, winding dielectric loss, short circuit impedance and insulation items. We have accurately judged the internal fault of the transformer core multi-point grounding of the transformer. It verifies the reliability of this transformer fault diagnosis method.

\section{References}

1. Xu Jiankang, Meng Yuchan. A practical technique for chromatographic analysis of dissolved gas in transformer oil[M]. Beijing: China Standards Press, 2011.

2. China electric power enterprise federation. Guide to the analysis and the diagnosis of gases dissolved in transformer oil. DL/T 722—2014[S]. Beijing: China Electric Power Press

3. Li Wenzhi. Analysis of Fault Causes of Excessive Characteristic Gas Content in Transformer Oil[J] Electrical \& Electronics.2019.10:39-41

4. Jin Daxin. Application examples of oil chromatographic characteristic gas analysis[J] Transformer, 2016, 53(6):71-72.

5. Liao Huaidong. Oil Chromatographic Analysis and Fault Diagnosis for Transformers[J] Hi gh Volt age Engineering2006,32(1)112-113 